\title{
Y-TZP 陶瓷中钇的晶界富集"
}

冯建雅 沈志坚王幼文 李廷凯

(浙江大学材料科学系,杭州 310027 )

关链词氧化铅、晶界、偏析

\section{一、引 㠵}

添加 $\mathrm{Y}_{2} \mathrm{O}_{3}$ 的四方 $\mathrm{ZrO}_{2}$ 多晶 $(\mathrm{Y}-\mathrm{TZP})$ 陶瓷是一类韧性极高的结构陶瓷材料, 其高韧 性主要来源于断裂过程四方 $\mathrm{ZrO}_{2}\left(\mathrm{I}-\mathrm{ZrO}_{2}\right)$ 的马氏体相变吸收了裂纹扩展能量. 而 $\mathrm{T}-\mathrm{ZrO}_{2}$ 的保留与相变特性除了与其在瓷体中所处的状态有关外, 直接依赖于稳定剂 $\mathrm{Y}_{2} \mathrm{O}_{3}$ 的含量以 及稳定剂离子 $\mathrm{Y}^{3+}$ 在其晶体中所占居的位置与分布. 已有很多工作研究了瓷体中 $\mathrm{T}-\mathrm{ZrO}_{2}$ 的 结晶形态及相变的成核与发展过程. 与之相比, 研究稳定剂离子 $\mathrm{Y}^{3+}$ 在 $\mathrm{T}-\mathrm{ZrO}_{2}$ 晶体中所 占位置及分布的工作很少. 我们在装备有能量色散 X 射线 (EDX) 谱仪的透射电镜 (TEM) 上测定了 Y-TZP 陶瓷中钎离子的分布情况, 发现了明显的钎非均匀分布现象. 本文报道这 一工作的初步结果. 深入研究钇非均匀分布现象将有助于更深人地理解 $\mathrm{Y}_{2} \mathrm{O}_{3}$ 稳定 $\mathrm{T}-\mathrm{ZrO}_{2}$ 的机理以及 $\mathrm{T}-\mathrm{ZrO}_{2}$ 的相变行为.

\section{二、实 验过程}

实验选用的研究对象为含 $8 \mathrm{wt} \% \quad \mathrm{Y}_{2} \mathrm{O}_{3}$ 的 $\mathrm{Y}-\mathrm{TZP}$ 陶瓷, 它是采用共沉淀方法制得的超 细粉末, 经 $1600^{\circ} \mathrm{C}, 1 \mathrm{~h}$ 热压烧结成瓷的. 瓷体组织中除了小颗粒的 $\mathrm{T}-\mathrm{ZrO}_{2}$ 晶粒外, 尚存在 一些大晶粒, 这些大晶粒据分析为立方 $\mathrm{ZrO}_{2}\left(\mathrm{C}-\mathrm{ZrO}_{2}\right)$ 或含有 $\mathrm{T}-\mathrm{ZrO}_{2}$ 析出物的 $\mathrm{C}-\mathrm{ZrO}_{2}$ 颗 粒 ${ }^{[1,2]}$. 实验测定了 $\mathrm{T}-\mathrm{ZrO}_{2}$ 晶粒内以及 $\mathrm{T}-\mathrm{ZrO}_{2}$ 晶粒间钎含量及其分布, 由电子衍射分析 确证各晶粒的晶相种类. 钎含量的测定在装备有 EDX 能谱的 JEM-100CX 透射电子显微 镜上进行. 测试所用透射样品直接切割自烧结瓷体, 经机械及手工磨抛至约 $30 \mu \mathrm{m}$, 再经离 子减薄至小于 $100 \mathrm{~nm}$.

选用 $\mathrm{Zr}-\mathrm{K}$ 和 $\mathrm{Y}-\mathrm{K}$ 发射线进行 EDX 定量分析,每个测试点计数时间为 $200 s$, 用简化 的 Cliff-Lorimer 方法 ${ }^{[3]}$ 计算钎含量. 根据薄片上污染斑的尺寸估计 X 射线激发区的宽度,即 空间分辨率值约在 $100 \mathrm{~nm}$ 左右.

\section{三、实验结果与讨论}

图 $1 \mathrm{a}$ 为 Y-TZP 陶瓷的 TEM 形貌像, 显示了三颗 $\mathrm{T}-\mathrm{ZrO}_{2}$ 晶粒及其相互间构成的晶 界,三颗晶粒构成三条二晶粒晶界和一个三晶界交汇点。实验测定了晶粒内、晶界上和三晶界 交汇点处钎含量及其分布情况. 测量的办法是沿着晶界或穿过晶粒一点一点地移动电子束,

本文 1989 年 10 月 16 日收到. 1990 年 1 月 15 日收到修改稿.

- 国家自然科学基金资助项目. 
逐点收集 EDX 谱. 图 2 示出了晶粒内、晶界上和三晶界交汇处典型的 EDX 谱, 作为参比, 反映瓷体内钎含量平均值的面分析 EDX 谱也一并示出. 图 3 显示了晶界上及晶粒内部钎含 量的分布情况, 图中 A、B、C、D 各点分别对应于图 1b 所示微观结构上的相应位置. 钎离子 在晶界附近明显富集, 远离晶界约 $200 \mathrm{~nm}$ 后, 晶粒内部钎含量低于瓷体内钎含量的平均值, 且

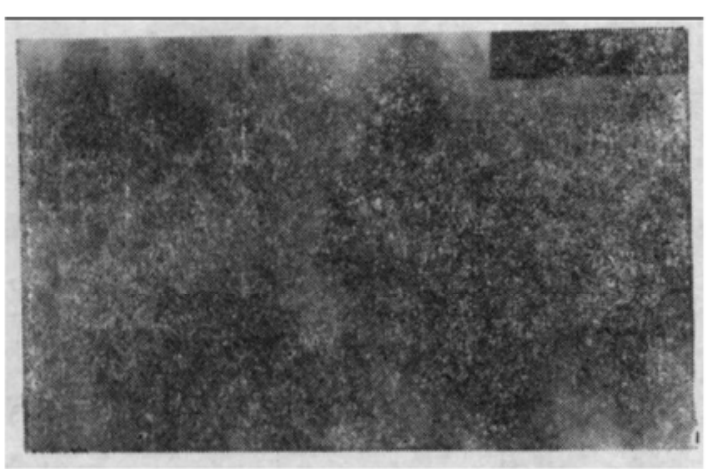

8

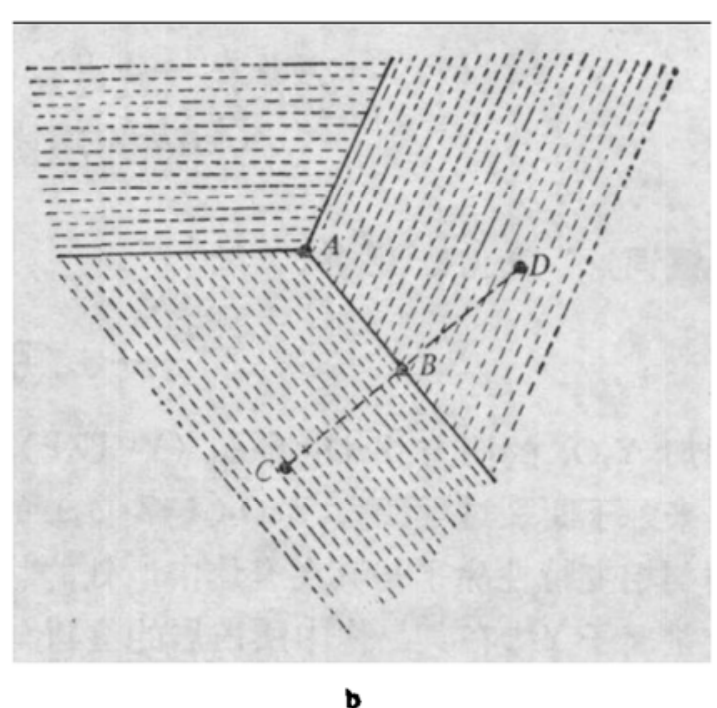

图 1 Y-TZP 陶瓷的 TEM 形貌像及 EDX 分析测试点分布示意图

2. Y-TZP 陶䘫的 TEM 形貌像,三颗 T-Z rO, 昆柆构成三条二晶柆晶界。山一个

三晶界交汇点 $(\times 57600) ;$ b. EDX 分析调试点的分布示意图

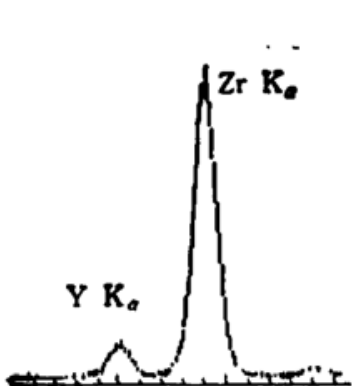

(a)

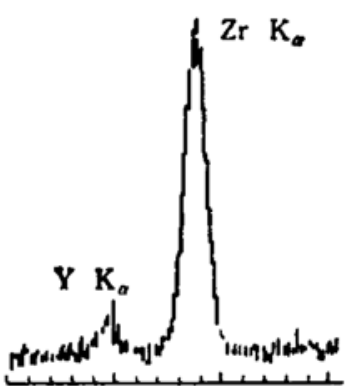

(b)

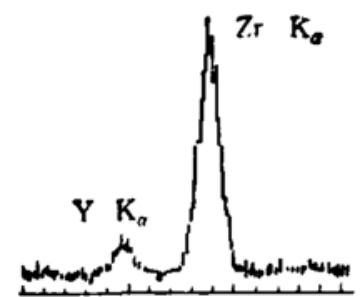

(c)

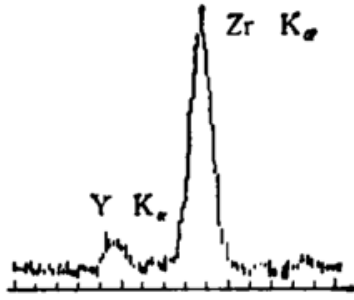

(d)

图 2 微观结构内各典型部位的 EDX潽

（a）面分析 EDX 谓; (b) $A$ 点对应的 EDX 僯; (c) $B$ 点对应的 EDX 谱; (d) $C$ 点对应的 EDX 证

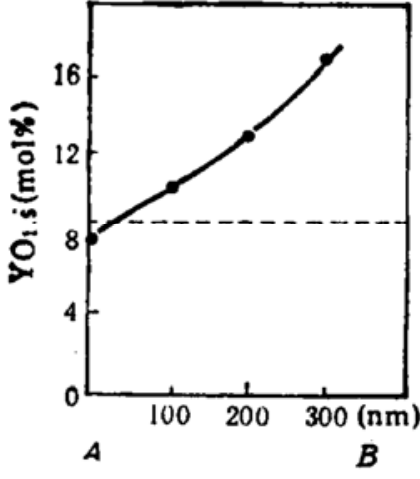

(a)

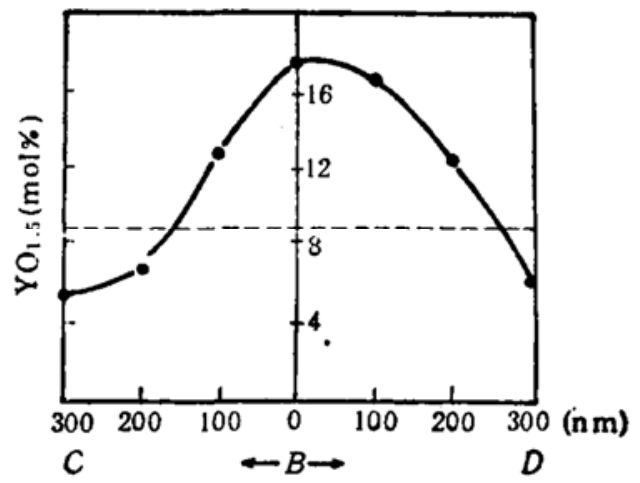

(b)

图 3 钎含量在晶界上 (a) 和晶柆内 (b) 的分布 䍀线所示为由面分析 EDX 所得瓷体内钎含策的平均值 
愈远离晶界, 钎含量愈低. 三晶界交汇处是晶界上钔含量的最低点, 远离三晶界交汇点的二晶 粒晶界上钔含量高于三晶界交汇点,且距离三晶界交汇点愈远, 钎含量愈高.

作者早先曾对共沉淀法制备 $\mathrm{Y}_{2} \mathrm{O}_{3}$ 稳定的 $\mathrm{ZrO}_{2}$ 粉体中钎、锆原子的近邻结构进行过研 究 ${ }^{[4]}$, 发现掺 $\mathrm{Y}_{2} \mathrm{O}_{3}$ 的 $\mathrm{T}-\mathrm{ZrO}_{2}$ 粉体中 $\mathrm{Y}-\mathrm{O}$ 间距明显较 $\mathrm{C}-\mathrm{ZrO}_{2}$ 中短, 从而认为 $\mathrm{Y}$ 原子富集 在 $\mathrm{T}-\mathrm{ZrO}_{2}$ 颗粒的表面. 瓷体内钎的晶界富集现象可能直接与此有关, 由于继承了烧结前 $\mathrm{T}-\mathrm{ZrO}_{2}$ 粉体颗粒中 $\mathrm{Y}$ 的表面富集习性,才导致瓷体内 $\mathrm{T}-\mathrm{ZrO}_{2}$ 晶粒界面间 $\mathrm{Y}$ 的富集现象. 瓷 体内三晶界交汇点在瓷体烧结成前为粉体颗粒堆积时留下的空洞,在瓷体通过表面扩散、晶界 扩散、晶格扩散等各种传质机制烧结成瓷的过程中, 各类离子向该空洞迁移、充填, 形成晶界. $\mathrm{Y}^{3+}$ 离子固溶于 $\mathrm{ZrO}_{2}$ 晶格后, 在 $\mathrm{ZrO}_{2}$ 晶格内引入氧空位, 该氧空位制约了 $\mathrm{Y}^{3+}$ 离子的迁 移, 所以在烧结的过程中, $\mathrm{Y}^{3+}$ 离子的迁移速率可能明显低于 $\mathrm{Zr}^{4+}$ 离子, 从而最终导致三晶 界交汇处 $\mathrm{Y}^{3+}$ 离子浓度较低. 而远离三晶界交汇点的晶界上某点, 在烧成前就是两颗粒的 接触点,在烧成过程中, 通过界面的移动, 晶粒长大并形成晶界. 一方面,界面的初始 $\mathrm{Y}$ 含畫较 高, 另一方面, 由于界面处的缺陷较多, 杂质离子容易富集, 因此, 其附近钎离子含量最高. 介 于该点与三晶界交汇点的晶界上任何一处, $\mathrm{Y}^{3+}$ 离子含量均随着烧结过程传质量的大小而改 变. 此外, 从烧结角度分析, 这种 $\mathrm{Y}^{3+}$ 离子在晶界附近的富集对烧结也是有利的, 因为它能降 低界面能, 从而增加烧结的驱动力.

钎离子非均匀分布的结果在瓷体内 $\mathrm{ZrO}_{2}$ 晶粒表层形成了一个富钎的壳层, 由图 3 可见, 该富钎壳层的厚度约在 $200 \mathrm{~nm}$ 左右. $\mathrm{T}-\mathrm{ZrO}_{2}$ 晶粒表层富钎壳层的形成, 对 $\mathrm{T}-\mathrm{ZrO}_{2}$ 产生了 一个约束, 有利于大颗粒或/和低钎含量的 $\mathrm{T}-\mathrm{ZrO}_{2}$ 的亚稳保留,而这种 $\mathrm{T}-\mathrm{ZrO}_{2}$ 的保留对相 变增㓞有积极的作用.

[1] Rahle, M., Chaussen, N., Neuer, A. H., Advances in Ceramics, Vol. 12, Science and Tcihnology of Zirconia II, American Ceramic Society, Columbus, OH, 1984, 352-370.

[2] Matsui, M., Soma, T. and Oda, I., Advances in Ceramics, Vol. 12, Science and Technology of Zirconia II, American Ceramic Society, Columbus, OH, 1984, 371--381.

[ 3] Hren, J. J., Goldstein, J. I. and Joy, D. C., Introdwction to Analyucal Electron Micruscopy, Plenum Press, New York, 1979. 83-167.

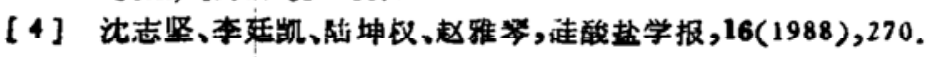

